\title{
Evaluation of GNSS monument stability
}

\author{
R. Haas \\ Department of Earth and Space Sciences \\ Chalmers University of Technology, Onsala Space Observatory, SE-439 92 Onsala, Sweden \\ E-mail: rudiger.haasechalmers.se \\ S. Bergstrand \\ SP Technical Research Institute of Sweden, Measurement Technology, SE-501 15, Borås, Sweden \\ W. Lehner \\ on the leave from the Institute of Geodesy and Geophysics, Vienna University of Technology, AT-1040 Wien, \\ Austria
}

\begin{abstract}
We report on an evaluation of the stability of four different GNSS monuments that was conducted in the summer of 2010. The monuments were monitored by forward intersections using a survey system consisting of two robotic total stations and a set of retro reflecting prisms. The system was operated for almost three months, performing observations in two faces with a repetition cycle of five minutes. Movements in excess of $6 \mathrm{~mm}$ were detected. The results show clear evidence that the detected deformations are related to variations in temperature and solar radiation and can be suppressed by simple shielding of the monument. Furthermore, our project is a step towards the realization of continuous cartesian connections at geodetic fundamental stations.
\end{abstract}

Keywords. geodetic monitoring, GNSS monuments, local-tie monitoring, fundamental geodetic stations, Global Geodetic Observing System (GGOS), co-located space geodetic techniques, continuous cartesian connections (CCC).

\section{Introduction}

Space geodetic techniques and their applications are today dominated by Global Navigation Satellite Systems (GNSS). One of the main objectives of static GNSS is to maintain local, regional, and global reference frames and networks. In Sweden, the National Land Survey (Lantmäteriet - LM) operates the SWEPOS network since the early 1990's. During the last years, LM has augmented the original network of 21 SWEPOS sites that are used for geophysical research, e.g. the BIFROST project (Scherneck et al., 2003), and the whole network now also comprises about 150 additional RTK-stations (SWEPOS, 2011). The original SWEPOS monuments consist of $3 \mathrm{~m}$ tall heated circular concrete pillars that are firmly connected to crystalline bedrock (Scherneck et al., 2002). The monuments were designed this high in order to guarantee full satellite visibility above 10 degrees of elevation, to prevent vandalism and disturbances due to people and animals, and to mitigate snow effects.

In the near future, the original 21 SWEPOS sites are to be equipped with additional GNSS monuments for redundancy purposes, and a favorable ratio of monument stability versus financial expense is sought for. The Onsala Space Observatory (OSO) is one of these 21 sites and the decision on the monument design requires a reliable stability evaluation.

On their homepage, UNAVCO (2011) suggests a number of monument designs utilized in different regional networks, and lists important aspects when choosing monuments. When external factors (multipath, elevation cut-off, ground stability etc.) are excluded, two important criteria for a good monument design remain: stability, and a narrow antenna mount within a wavelength from the antenna base; the latter to not interfere with satellite signal reception.

However, the basis for assessments of monument stability is usually derived directly from GNSS results, e.g. Williams et al. (2004); Beavan (2005); Bergstrand et al. (2005); Langbein (2008). As an alternative, independent measurements can be performed with classical geodetic survey techniques. These techniques allow high precision in the local frame and high temporal resolution. In the summer of 2010 we evaluated the stability of four GNSS monument designs at OSO.

\section{GNSS-monuments}

At OSO, Precambrian crystalline bedrock is exposed at large parts of the observatory. Four GNSS monuments were erected within an area of $10 \mathrm{~m} \times 10 \mathrm{~m}$.

The first monument was a $3.20 \mathrm{~m}$ high truss mast with a triangular cross section used in tempo- 
rary real-time-kinematic (RTK) networks and was provided by LM for the investigation. Haas and Bergstrand (2010a) indicated a potential bending effect of truss masts with quadratic cross section due to differential solar heating, and LM has pondered upon a solution to prevent potential vandals from climbing the antenna. We therefore agreed to evaluate the effect of a shield made of a plastic sewage pipe around the truss mast, and compare the shielded and unshielded mast over periods long enough to achieve responses that are representative of the ambient conditions.

The other three monuments were manufactured at the workshop at OSO. The hexagonal mast of $3.20 \mathrm{~m}$ height is an extended version of the design used for the mounting of small so-called Salsa radio telescopes at OSO. The Earlconic mast follows the design used by the Michigan Department of Transportation (2011). It is a steel pipe with reinforcement gussets and was also constructed to be $3.2 \mathrm{~m}$ high. The fourth mast is a $1.25 \mathrm{~m}$ high welded reinforced tripod constructed to resemble the shallow drilled braced monument (SDBM) as described by UNAVCO (2011). The four monuments are described in more detail by Lehner (2011).

The narrow base of the Earlconic and Salsa monuments allowed for horizontal fixations, whereas the considerably wider base of the SDBM monument was adjusted to the rock surface by subsequent telescopic extension of the three outwards pointing legs and fastening. Figure 1 shows the four monuments set up at OSO.

\section{Survey method}

The developed survey method is based on the most accurate method for classical surveying with theodolites: the standard method of forward intersection observing a target with double instruments in two faces. The advantages of the method are measurement redundancy and that the weakest part of the measurement system - the electronic distance meter (EDM) - is largely omitted. A detailed description of the method is provided by Lehner (2011).

We deployed two Leica TS30 robotic total stations (Zogg et al., 2009) to monitor Leica GMP 104 prisms and Leica RFI reflectors. The two total stations were attached to tribraches that were mounted directly in the bedrock and formed a baseline of about $3.5 \mathrm{~m}$ length with east-west orientation. We refer to an eastern and western total station in the following. The utilized coordinate system is based on the direction between these two stations and may deviate slightly

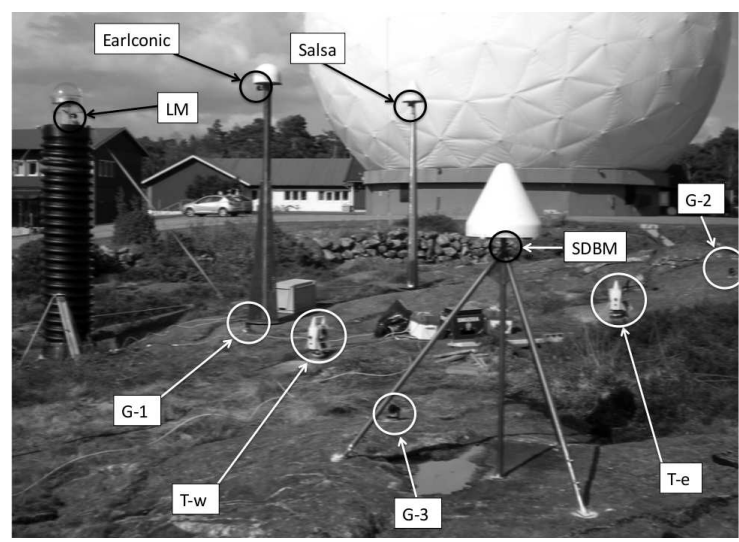

Fig. 1 Picture of the small survey network at the Onsala Space Observatory. Shown are the two total stations T-w (total station west) and T-e (total station east), the three suryey prisms G-1, G-2, G-3 mounted directly in bedrock, and the four prisms mounted on the LM, Earlconic, Salsa, and SDBM monument.

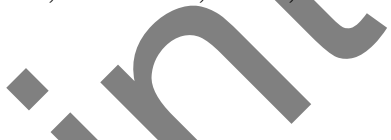

from true east and north. Around the two total stations, three survey prisms were mounted directly in bed rock. The target reflectors were mounted at the monument tops adjacent to the antenna mounts (Fig. 1), in order to represent potential movements of the antennas. The two total stations were PC controlled with the Leica GeoMoS 5.0 software, which handled the measurement cycle and logging of data. Observations were done almost continuously from mid of May to mid of August 2010. Additionally, air and material temperature observations were made throughout the campaign.

As the hair cross of modern total stations cannot be observed backwards through the optics as in classic forward intersection, a traditional alignment of the two total stations is not possible. Instead, the orientation and the distance between the two total stations were determined from redundant observations of a calibrated scale bar that was set up in four geometrically well distributed positions with respect to the baseline between the total stations. A Newton iteration method was then used to determine the relative orientation of the two total stations, and the distance between them, thus defining the scale. The uncertainty of the relative orientation was estimated to be 0.15 mgon, based on a variation analysis. The distance estimate between the two total stations was verified by interferometric laser tracker measurements to be in agreement on the $0.1 \mathrm{~mm}$ level. 


\section{Data analysis and results}

The raw data taken with the pair of robotic total stations were analyzed in post-processing. The measurements to the reference survey prims mounted directly in solid bedrock were used to check the stability of the survey system. The time series of horizontal angles for these prisms show small diurnal sinusoidal signatures with amplitudes of up to 4 mgon, and a drift of 10 mgon during the whole campaign. Based on these measurements, corrections for the horizontal angles to all other targets were applied on an epoch by epoch basis. Forward intersection was then applied to determine time series of local xyzcoordinates for the prisms. These time series reveal movements on the order of up to $6 \mathrm{~mm}$, in particular for the horizontal components. As an example, Figure 2 presents time series for xyz-coordinates during six days in the end of May and beginning of June 2010, together with the recorded ambient temperature. Temperature and coordinate variations show a similar pattern, with temperature ahead in the time domain.

The coordinate uncertainties were derived by error propagation, using the instrumental precision of the total stations as provided by the manufacturer and the geometrical situation. For the four investigated monuments the expected uncertainties for the coordinate determination were between $0.01 \mathrm{~mm}$ and $0.15 \mathrm{~mm}$ for the $\mathrm{X}-, 0.02 \mathrm{~mm}$ and $0.15 \mathrm{~mm}$ for the $\mathrm{Y}-$ $0.03 \mathrm{~mm}$ and $0.09 \mathrm{~mm}$ for the Z-component.

Figure 3 shows the coordinate variations in the xy-plane. The two designs that exhibit larger movements are the gusset enforced Earlconic and the Salsa monument. For the Salsa monument, which in all essence is symmetrical, the elliptical pattern reflects the difference between the large thermal gradients when the sun rises and sets and the smaller gradients at noon. The Earlconic monument exhibits movements of the same magnitude as the Salsa monument, but the movement directions are confined to those of the gussets. Considerably smaller are the movements of the truss mast and the SBDM. When comparing the smaller movements of these two monuments, one should remember that the height ratio of the two monuments are almost $3: 1$, which inhibits a direct comparison. However, both movements have a strong directional signature. This is comprehensible for the SBDM which have tripod-like features similar to the Earlconic monument, but is not as obvious for the truss mast.

Investigating the truss mast a bit further, we compare the truss mast when being shielded from the sun

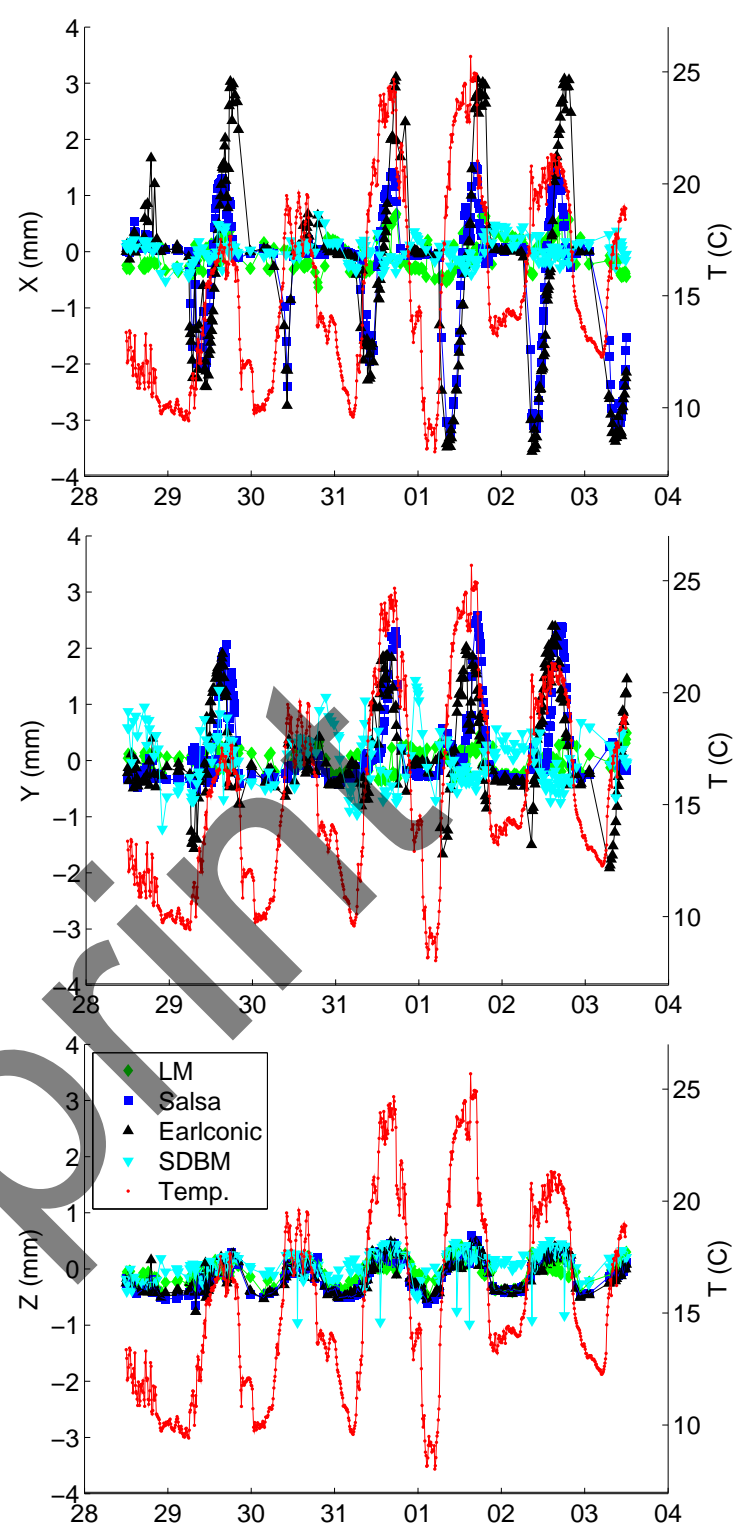

Fig. 2 X-, Y- and Z-coordinates (top, middle and bottom plot) of the survey prisms on four monuments (left scale), together with the recorded ambient temperature (right scale) during six days in the end of May/beginning of June.

with a plastic tube to being fully exposed. The effect of the shield is shown when comparing the graphs in Fig. 4, which were recorded under similar conditions. In the top graph of Fig. 4, the shield was fitted around the monument and the movements are orientated between the second and fourth quadrant, which is quite contrary to the other monuments. When taking a closer look at the figure, there appears to be 


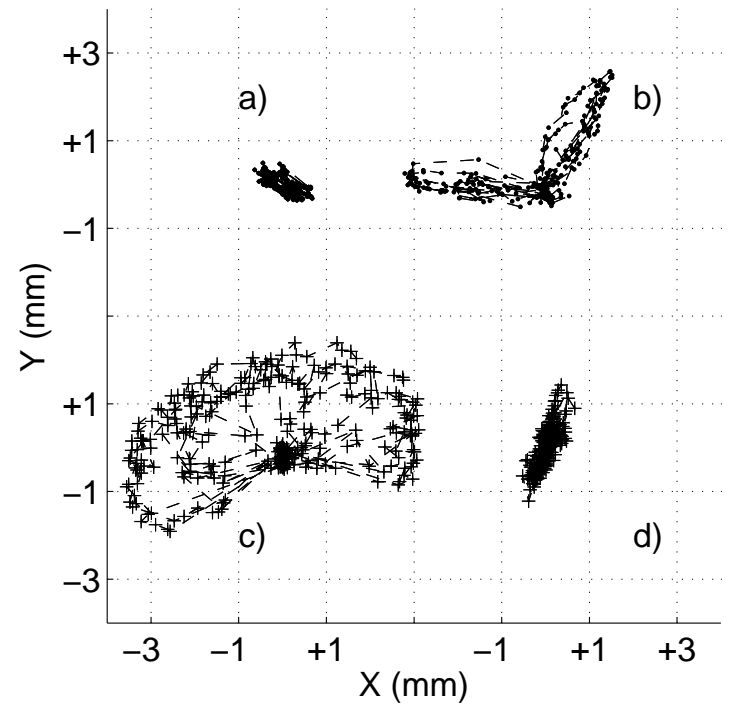

Fig. 3 Horizontal positions of the survey prisms mounted at the top of the four monuments during 6 sunny days in the end of May and beginning of June 2010. Shown are (a) the truss mast (LM), (b) the Earlconic, (c) the Salsa, and (d) the SDBM monument. The shown values refer to a mean position for each of the prisms. The values for the individual prisms are offset from each other by $3 \mathrm{~mm}$ in $\mathrm{X}$ and Y for improve visibility and allow easy comparison. The size of the crosses represent the measurement uncertainty of each individual measurement.

two populations. It turns out that the direction coincides with that of a flat bar iron mounted on top of the mast to move the antenna ground plane away from metal objects and in order to improve signal reception. Even so, the observations can almost be circumscribed by a circle of $1 \mathrm{~mm}$ diameter. When the shield has been removed, the noise level increase beyond the $1 \mathrm{~mm}$ diameter, see the bottom graph in Fig. 4, but the pattern is not as articulate as for the solid Salsa and Earlconic monuments. This probably reflects that the solar heating through the truss is constantly changing due to the irregular shape. Nevertheless, the directivity remains and it appears that the flat bar still has considerable impact on the movements.

Figure 5 presents the relation of ambient temperature and Z-component for the four monuments. Vertical movements on the range of $1 \mathrm{~mm}$ are detected, corresponding to temperature changes of about 15 degrees Celsius. The Earlconic and Salsa monuments show a larger deformation than the other monuments, which can be explained by that the LM mon-
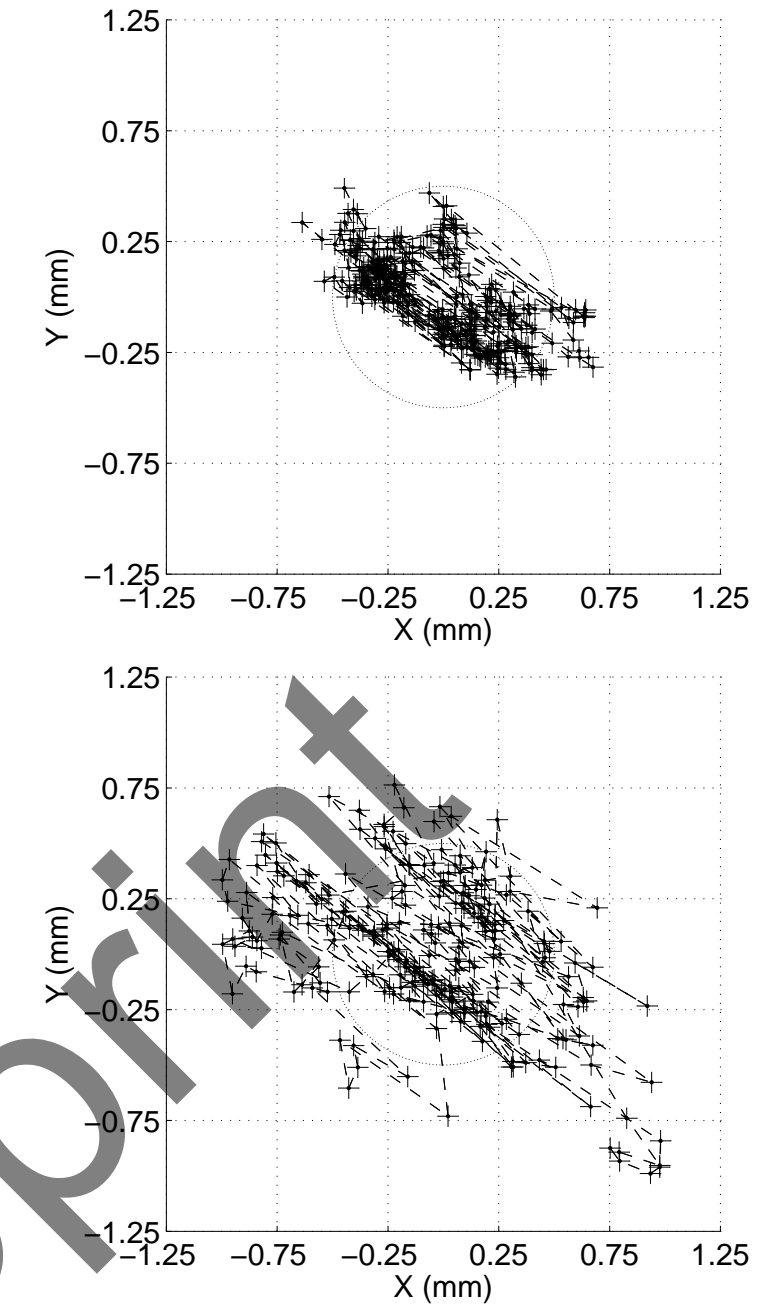

Fig. 4 Horizontal positions of the survey prism mounted at the top of the truss mast (M-T) during several days when the mast was covered by a protective pipe (top graph), and when the monument was not covered by a protective pipe (bottom graph). The shown values refer to a mean position and the dotted circle has a diameter of $1 \mathrm{~mm}$. The size of the crosses represent the measurement uncertainty of each individual measurement.

ument was shielded from direct solar radiation, and that the SDBM monument is shorter than the others. 


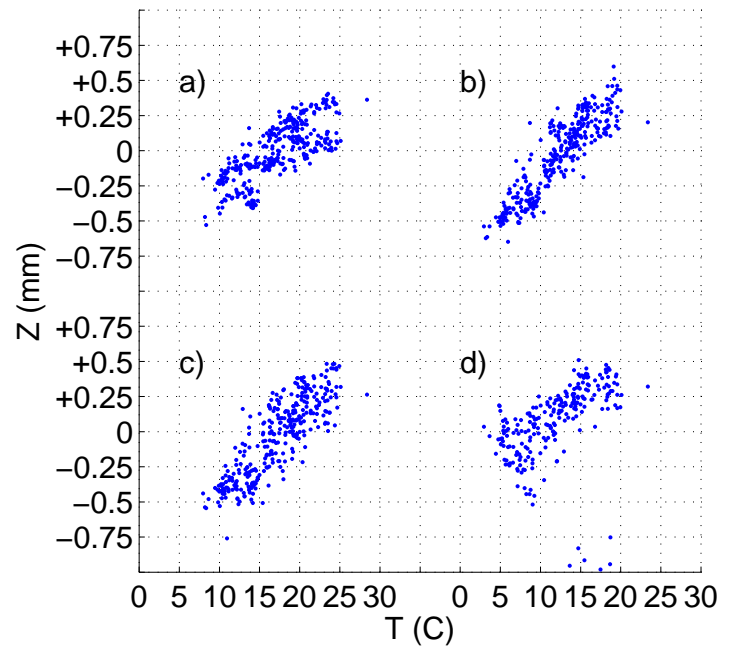

Fig. 5 Scatter plots of Z-coordinate versus ambient temperature. Shown are (a) the truss mast (LM), (b) the Earlconic, (c) the Salsa, and (d) the SDBM monument.

\section{Conclusions and outlook}

We developed a survey method to continuously observe local movements of GNSS monuments and employed it for three months. This method uses two computer controlled robotic total stations in a forward intersection approach and provides time series of monument positions with high accuracy and high temporal resolution.

Our results reveal a clear connection between temperature and deformation of GNNS monuments, both in the horizontal and the vertical domain. Effects like these are of course expected and the vertical movements can probably be modeled with good performance based on temperature and material properties. However, figures 3 and 4 prove that the movement patterns reflect solar interaction with the monument geometry, and show that thermal expansion due to solar heating is an important factor when space geodetic observations need to be fine-tuned. As the observed patterns are asymmetrical, the solar induced movements will cause biases of the monument position estimates. Nevertheless, the patterns seem to motivate the use of lighter monument constructions, e.g. truss masts, probably due to improved heat dissipation and reduced thermal expansion. Shielding of the monument proved to significantly reduce the observed movements and should be applicable to all designs. It goes without saying that had the antenna support atop the truss mast been symmetrical and shaded, the movements could probably have been suppressed further. GNSS signal reception must not be compromised, but complementing the current shield design with a thinner plastic tube outside the support could be made without disturbing the antenna pattern. Note that the bedrock at OSO is very stable and that the presented evaluation addresses monument movements above ground only. Other aspects that might be more important for some applications (e.g swaying during rapid earth movements) have not been addressed.

The presented survey method appears to be well applicable to local tie surveys as well as the proposal for continuous cartesian connections (CCC) at fundamental geodetic stations (Haas and Bergstrand, 2011). A continuous monitoring with high accuracy and high temporal resolution is relevant for Global Geodetic Observing System (GGOS) (Rummel et al., 2005). The GGOS intends to combine and integrate different geodetic techniques in order to exploit the individual strength of the techniques and thus depends on that local ties between co-located geodetic techniques at fundamental geodetic stations are known with an accuracy on the order of $0.1 \mathrm{~mm}$ (Rothacher et al, 2009; Ray and Altamimi, 2005; Altamimi et al., 2007). Our method is a first step to realize this ambitious goal.

The next step in the system development is to oberve targets on a moving platform (e.g. a VLBI telescope) during operation and to monitor several reference points at a co-location station with high temporal resolution.

\section{Acknowledgement}

We thank Christer Thunell from Leica Geosystems Sweden, Magnus Herbertsson from SP Technical Research Institute of Sweden, Lasse Wennerbäck, Christer Hermansson, and Håkan Millqvist from the OSO workshop for their support.

\section{References}

Altamimi Z., Collilieux X., Legrand J., Garayt B., Boucher C. (2007) ITRF2005: A new release of the International Terrestrial Reference Frame based on time series of station positions and Earth Orientation Parameters. J Geophys Res, 112, B09401, doi:10.1029/2007JB004949

Beavan J. (2005) Noise properties of continuous GPS data from concrete pillar geodetic monuments in New Zealand and comparison with data from U.S. deep drilled braced monuments. J Geophys Res, 110, B08410, doi:10.1029/ 2005 JB003642

Bergstrand S., Scherneck H.-G., Lidberg M., Johansson J.M. (2005) BIFROST: Noise properties of GPS time series. in 
Dynamic Planet, International Association of Geodesy Symposia, 2007, Vol. 130, Part II, 123-130, doi:10.1007/ 978-3-540-49350-1_20

Haas R., Bergstrand S. (2010) COLD MAGICS - Continuous Local Deformation Monitoring of an Arctic Geodetic Fundamental Station. In: International VLBI Service for Geodesy and Astrometry 2010 General Meeting Proceedings, edited by D. Behrend and K. D. Baver, NASA Conference Publication, NASA/CP-2010215864, 118-120

Haas R., Bergstrand S. (2011) Continuous Cartesian Connections at Geodetic Collocation Sites. in preparation.

Langbein J. (2008) Noise in GPS displacement measurements from Southern California and Southern Nevada. J Geophys Res, 113, B05405, doi:10.1029/2007JB005247

Lehner W. (2011) Evaluation of environmental stress on GNSSmonuments. MSc thesis, Chalmers University of Technology and Technical University of Vienna, 2011, in preparation

Michigan Department of Transportation (2011), http: //www . mdotcors.org/

Ray J., Altamimi Z. (2005) Evaluation of co-location ties relating the VLBI and GPS reference frames, J Geodesy, 79, 189-195, doi:10.1007/s00190-005-0456-z.

Rothacher M., Beutler G., Bosch W., Donnellan A., Gross R., Hinderer J., Ma C., Pearlman M., Plag H.-P., Richter B., Ries J., Schuh H., Seitz F., Shum C.K., Smith D., Thomas M., Velacognia E., Wahr J., Willis P., Woodworth P. (2009) The future Global Geodetic Observing System. in: Global Geodetic Observing System, edited by H.-P. Plag and M. Pearlman, Springer-Verlag, Heidelberg/Berlin, 237-72, doi:10. 1007/978-3-642-02687-49

Rummel R., Rothacher M., Beutler G. (2005) Integrated Global Geodetic Observing System (IGGOS) - science rationale. J Geodyn, 40, 357-362

Scherneck H.-G., Johansson J.M., Elgered G., Davis J.L., J son B., Hedling G., Koivula H., Ollikainen M., Poutanen M., Vermeer M., Mitrovica J.X., Milne G.A. (2002) BIFROST: Observing the Three-Dimensional Deformation of Fennoseandia. In: Glacial Isostatic Adjustment and the Earth System, J.X. Mitrovica and B.L.A. Vermeersen (eds.), Geodynamics Series, 29, American Geophysical Union, 69-93.

Scherneck H.-G., Johansson J.M, Koivula H., van Dam T., Davis J.L. (2003) Vertical crustal motion observed in the BIFROST project. $J$ Geodyn, 35, 425-441, doi:10.1016/S0264-3707(03)00005-X.

SWEPOS - A National network of reference stations for GPS. http://swepos.lmv.lm.se/english/index.htm

UNAVCO Resources: GNSS Station Monumentation, http: / / facility.unavco.org/kb/questions / 104 /UNAVCO+Resources\%3A+GNSS+Station+ Monumentation

Williams S.D.P., Bock Y., Fang P., Jamason P., NikolaidisR.M., Prawirodirdjo L., Miller M., Johnson D.J. (2004) Error analysis of continuous GPS position time series, J Geophys Res, 109, B03412, doi:10.1029/2003JB002741

Zogg H.-M., Lienhart W., Nindl D.(2009) Leica TS30 White Paper. Leica Geosystems AG, Heerbrugg, Switzerland. http://www.leica-geosystems. com/downloads123/zz/tps/general/ white-tech-paper/WhitePaper_TS30_en.pdf 